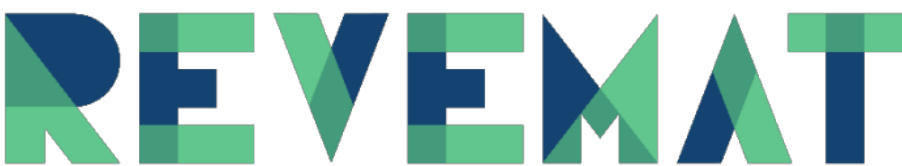

REVISTA ELETRÔNICA DE EDUCAÇÃO MATEMÁTICA

\title{
FORMAÇÃO CONTINUADA DE PROFESSORES DE MATEMÁTICA PARA USO DE TECNOLOGIAS DIGITAIS: UMA ANÁLISE A PARTIR DE UM CURSO DE EXTENSÃO SOBRE O SOFTWARE SCRATCH \\ Continuing training of mathematics teachers for the use of digital technologies: an analysis from an extension course on the Scratch software
}

\author{
Flavia Sucheck Mateus da ROCHA \\ Centro Universitário Internacional Uninter, Curitiba, PR \\ fsucheck@yahoo.com.br \\ (7) https://orcid.org/0000-0001-6803-8898
}

Tânia Teresinha Bruns ZIMER Universidade Federal do Paraná, Curitiba, PR taniatbz@gmail.com

(1) http://orcid.org/0000-0002-9353-7944

Sérgio CAMARGO Universidade Federal do Paraná, Curitiba, PR s1.camargo@gmail.com (1) https://orcid.org/0000-0001-8766-5424

Marcelo Souza MOTTA Universidade Tecnológica Federal do Paraná, Curitiba, PR msmotta27@gmail.com

(b) https://orcid.org/0000-0001-5534-2735

A lista completa com informações dos autores está no final do artigo

\begin{abstract}
RESUMO
As tecnologias digitais podem representar novas possibilidades metodológicas para os processos de ensino e aprendizagem de Matemática, principalmente quando os docentes envolvidos com o uso de tais recursos conhecem suas potencialidades e funcionalidades. Com o objetivo de analisar as possíveis contribuições de um curso de formação continuada para professores de Matemática sobre o software Scratch, realizou-se uma investigação qualitativa do tipo estudo de caso, pautada no seguinte problema: quais as possíveis contribuições de um curso de formação de professores sobre o software Scratch na atuação profissional dos participantes? A partir da observação de um curso de extensão desenvolvido em um Grupo de Pesquisas sobre Tecnologias na Educação Matemática, que teve 14 participantes, efetuouse o registro dos dados de cada encontro do curso, bem como da participação dos cursistas. Um ano após a conclusão do curso, os participantes foram entrevistados para verificar como estava a prática profissional atual, buscando-se indícios das contribuições do curso. Para analisar os dados, utilizou-se o método de análise de conteúdo. Foi possível identificar que o curso, mais do que contribuir para que os participantes conhecessem um recurso diferenciado para a sala de aula, possibilitou que os professores se tornassem mais autônomos na busca de tecnologias digitais que contribuíssem com o aprimoramento da aprendizagem de seus alunos. O aprendizado coletivo, vivenciado em um grupo de pesquisa, possibilitou que esses professores permanecessem em formação e compartilhamento de conhecimentos.
\end{abstract}

Palavras-chave: Formação continuada, Formação de professores, Tecnologias Digitais, Scratch, Matemática 


\begin{abstract}
Digital technologies can represent new methodological possibilities for the teaching and learning processes of Mathematics. For these possibilities to be beneficial to the pedagogical processes, the teachers involved with the use of such resources must know their potential and functionalities. In order to analyze the possible contributions of a continuing education course for Mathematics teachers on the Scratch software, a qualitative investigation of the case study type was carried out, based on the following problem: what are the possible contributions of a training course of teachers about the Scratch software in the professional performance of the participants? From the observation of an extension course developed in a Research Group on Technologies in Mathematics Education, which had 14 participants, the data of each meeting of the course was recorded, as well as the participation of the course participants. One year after the conclusion of the course, the participants were interviewed to check on their current professional practice, looking for evidence of the course's contributions. To analyze the data, the content analysis method was used. It was possible to identify that the course, more than contributing for the participants to know a differentiated resource for the classroom, made it possible for teachers to become more autonomous in the search for digital technologies that would contribute to the improvement of their students' learning. Collective learning, experienced in a research group, made it possible for these teachers to remain in training and knowledge sharing.
\end{abstract}

Keywords: Continuing education, Teacher training, Digital Technologies, Scratch, Math

\title{
1 INTRODUÇÃO
}

Buscar novas formas de ensinar Matemática vem sendo tema de discussão por professores e pesquisadores ao longo dos anos. As chamadas tendências em educação matemática surgem no âmbito nacional na década de 1980 como alternativas de mudanças nos processos de ensino e aprendizagem da disciplina.

Entre essas tendências, as Tecnologias Digitais (TD) representam possibilidades de alterações pedagógicas, que podem colocar os estudantes como protagonistas em sala de aula (Borba, Silva \& Gadanidis, 2016). Elas contribuem para que modelos de aulas tradicionais, com predomínio de aulas expositivas, sejam alterados para ambientes colaborativos, de interação e interatividade ${ }^{1}$.

Essas tecnologias já fazem parte da vida do estudante e da sociedade como um todo, alterando as formas de comunicação e obtenção de informação. Mesmo assim, em muitos casos, elas não causam o mesmo impacto de mudança no âmbito escolar, seja por resistência do professor ou por problemas técnicos que impedem suas utilizações.

Além da possibilidade de mais envolvimento do estudante no processo de aprendizado, destacada por Borba et al. (2016), as TD podem ser exploradas para o desenvolvimento do Pensamento Computacional do estudante. Esse pensamento, propiciado pela resolução de problemas com uso de recursos informáticos, pode desenvolver variadas habilidades, como criatividade, resolução de problemas e facilidade

\footnotetext{
${ }^{1}$ Os termos interação e interatividade são usados neste trabalho de acordo com o entendimento de Belloni (1999), que considera interação as relações entre as pessoas e interatividade as relações do homem com a tecnologia.
} 
para o trabalho em equipe (Resnick et al., 2009). Os próprios documentos oficiais brasileiros vêm estimulando o desenvolvimento do Pensamento Computacional (Brasil, 2017) e a universalização do acesso à internet nas escolas (Brasil, 2014), o que revela a importância de professores conhecerem recursos nesse viés.

Nesse sentido, um software que pode ser explorado por professores é o Scratch. Ele possibilita que pessoas sem conhecimentos específicos desenvolvam programações por meio de blocos semelhantes às peças de um quebra-cabeças. Essas programações podem conduzir ao desenvolvimento do Pensamento Computacional (Resnick et al., 2009).

Contudo, mesmo que seja um software de programação intuitiva, nem todo professor se sente confortável para experimentar essa e outras TD em suas aulas. A resistência do professor em explorar novos recursos pode ser minimizada por meio de cursos de formação continuada (Richit, Mocroski \& Kalinke, 2016; Kenski, 2011).

De modo a incentivar professores a utilizarem o Scratch como recurso pedagógico em aulas de matemática, o Grupo de Pesquisas sobre Tecnologias na Educação Matemática $\left(\right.$ GPTEM $\left.^{2}\right)$ ministrou um curso de formação continuada, em caráter de extensão, no segundo semestre de 2017, a partir de reivindicações dos próprios participantes do grupo.

Uma das pesquisadoras, autoras desse artigo, participou do curso, realizando observações participativas. Findado o curso, algumas inquietações a respeito do caráter formativo levantaram alguns questionamentos: (a) os professores que realizaram o curso estavam utilizando o Scratch?; (b) cursos de formação sobre o Scratch auxiliam os professores de Matemática a incorporar o uso de TD na sala de aula?

Para sanar essas inquietações, realizou-se, inicialmente, uma revisão de literatura, tendo como base o Catálogo de Teses e Dissertações da CAPES. Localizaram-se 54 trabalhos a partir dos termos "formação" e "scratch". Porém, analisando os títulos e resumos desses, percebeu-se que apenas três trabalhos (Rocha, 2015; Farias, 2017; Rocha, 2018) tratavam de pesquisas sobre a formação do professor de Matemática para o uso do Scratch. O trabalho de Rocha (2015) analisou a integração entre o conhecimento tecnológico e o conhecimento de conteúdo do professor de Matemática. As pesquisas de Farias (2017) e Rocha (2018) tiveram como foco os projetos desenvolvidos pelos professores durante um curso de formação sobre o referido software. Compreendeu-se, assim, que investigar o além de um processo formativo, analisando as possíveis

\footnotetext{
${ }^{2}$ Maiores informações sobre o grupo de pesquisa podem ser obtidas em: https://gptem5.wixsite.com/gptem. Acesso em: 30 maio 2020.
} 
apropriações do curso na prática docente, poderia trazer novas contribuições para a comunidade científica.

Desse modo, desenvolveu-se uma pesquisa cujo objetivo foi o de verificar as contribuições do curso de formação sobre o Scratch na prática profissional dos professores envolvidos. O problema de pesquisa foi: quais as possíveis contribuições de um curso de formação de professores sobre o software Scratch na atuação profissional dos participantes? Para atingir o objetivo investigativo, realizou-se uma pesquisa qualitativa, por meio de um estudo de caso. Para a análise dos dados, foi utilizada a Análise de Conteúdo (AC) proposta por Bardin (2016).

O presente artigo apresenta, em sua introdução, a justificativa para a pesquisa, o objetivo geral e o problema de pesquisa. Na seção 2, é apresentada a fundamentação teórica da pesquisa. A seção 3 traz os aspectos metodológicos que conduziram a investigação e a análise. Nas seções 4 e 5 é apresentado o curso de formação e discutido, respectivamente. Em seguida, apresenta-se a análise dos dados e finalmente as considerações dos pesquisadores.

\section{FUNDAMENTAÇÃO TEÓRICA}

Pesquisadores e professores buscam alternativas que possam contribuir para que ocorram mudanças nos processos de ensino e aprendizagem. Por outro lado, as mudanças que acontecessem na sociedade também requerem alterações nos processos educacionais. Segundo Garcia (1999), as mudanças sociais, econômicas, tecnológicas e científicas impulsionam novas necessidades profissionais. Essas necessidades podem ser supridas por meio da formação, que é classificada pelo autor como o instrumento mais eficaz para que ocorra a democratização do acesso à cultura, trabalho e informação.

Garcia (1999, p. 22), ao apresentar os conceitos de formação de professores, relata que quando ela é entendida como um ensino que profissionaliza o ensino, pode ser conceituada como "um encontro entre pessoas adultas, uma interação entre formador e formado, com uma intenção de mudança, desenvolvida num contexto organizado e institucional mais ou menos delimitado". Imbernón (2010) converge com o autor ao indicar que a formação docente é um processo para a mudança.

A formação de professores pode ser considerada um processo contínuo, não se encerrando após a conclusão da graduação. Para Mizukami (2006, p. 214), “os processos 
de aprender e ensinar, de aprender a ser professor e de desenvolvimento profissional de professores são lentos, iniciam-se antes do espaço formativo dos cursos de licenciatura e se prolongam por toda a vida".

Desse modo, a formação continuada de professores é uma necessidade que possibilita que o professor permaneça em um processo de aprendizagem. De acordo com Nóvoa (2012), ela pode suprir determinadas carências da formação inicial. Nesse sentido, quando se discute a inserção das TD no contexto escolar, espera-se que o professor busque continuamente processos formativos, de modo a conhecer recursos e metodologias que se atualizam constantemente.

Além de contribuir com a aprendizagem do professor, a formação continuada pode impactar os processos de ensino. Romanowski (2007) aponta que a formação visa melhorar o ensino, não somente o profissional. Contudo, a autora menciona que para que o professor mude suas metodologias ele precisa ter essa pré-disposição, já que problemas e pressões "das situações em aula exigem do professor novas respostas alterando os procedimentos. São possibilidades para introduzir inovações na prática pedagógica. As mudanças incluem a qualificação e melhoria da prática" (Romanowski, 2007, p. 137). Assim, a formação continuada possui uma relação direta com a prática do professor. Alguns autores como Nóvoa (2012), Pimenta (2012), Tardif (2014) e Fiorentini, Souza Junior e Melo (2003) destacam a prática docente como fundamental aos processos formativos.

Nóvoa (2012, p. 15) defende que "propostas teóricas só fazem sentido se forem construídas dentro da profissão, se contemplarem a necessidade de um professor atuante no espaço da sala de aula". O autor ainda destaca a necessidade de que a formação teórica repercuta uma determinada reflexão dos professores.

Ao encontro do destaque de Nóvoa (2012), Pimenta (2012) alerta que a formação deve considerar a prática docente como ponto de partida e chegada. Na mesma vertente, Fiorentini, Souza Junior e Melo (2003) apontam que existe uma relação entre os saberes que o docente possui, seus modos de ser e agir e sua prática profissional.

Nóvoa (2012, p. 14) traz reflexões sobre a importância de os discursos progressistas sobre formações de professores se tornarem ações reais. O autor destaca que a formação deve ocorrer a partir de dentro da profissão, "reforçando os professores no seu papel e na sua capacidade de decisão e de ação". Corroborando com esse entendimento, Tardif (2014) comenta que os professores devem ser considerados parceiros e atores da sua própria formação. O autor adverte para a necessidade de se considerar a subjetividade do professor de modo a torná-lo autônomo. 
Também se referindo à autonomia do professor, Pimenta (2012, p. 32) apresenta a proposta de autoformação, "num processo coletivo de troca de experiências e práticas". Nesse sentido:

É o apoderamento da formação passando a ser parte intrínseca da profissão se o professorado quer ser protagonista de sua formação e desenvolvimento profissional. E esse protagonismo é necessário e, inclusive, imprescindível para poder realizar inovações e mudanças na prática educativa e desenvolver-se no pessoal e no profissional (Imbernón, 2009, p. 77).

Desse modo, percebe-se que o sujeito professor quando assume um papel ativo em sua formação pode desenvolver estratégias que o levem a resolver problemas em sua prática profissional. Nesse entendimento, Romanowski (2007) comenta sobre a importância de que sejam conhecidas as demandas e necessidades do professor, ao se elaborar processos de formação continuada.

Para o sucesso de um programa de formação continuada, é importante a realização de diagnóstico das necessidades formativas dos professores, ou seja, um dos princípios dos programas de formação de professores consiste em fornecer respostas para as necessidades de desenvolvimento profissional indicadas por eles (Romanowski, 2007, p. 138).

Contudo, resolver problemas da realidade da sala de aula ou carências diversas dos professores, como dificuldades com o uso das TD, não pode se limitar a meras instrumentalizações. Imbernón (2010) indica a necessidade de um conhecimento profissional ativo que contribua com a autonomia do professor, para que ele crie possibilidades e não apenas use instrumentalizações previamente elaboradas.

Entre as características necessárias para promover esse conhecimento profissional ativo, a formação permanente não deve oferecer apenas novos conhecimentos científicos, mas principalmente processos relativos a metodologias de participação, projetos, observação e diagnóstico dos processos, estratégias contextualizadas, comunicação, tomada de decisões, análise da interação humana (Imbernón, 2010, p. 74).

Esses processos podem ser desenvolvidos com a valorização da coletividade. Fiorentini, Souza Junior e Melo (2003) advertem para a necessidade de parcerias entre os professores, por meio de uma rede de interconexões. Os autores sugerem, que, ao invés de transmissão de conhecimentos, ocorra encorajamento aos professores para que desenvolvam autonomia para elaborarem inovações curriculares.

Segundo Garcia (1999, p. 21) "a inter-relação entre as pessoas promove contextos de aprendizagem que vão facilitando o complexo desenvolvimento dos indivíduos que 
formam e que se formam". Nesse viés, grupos de pesquisas são exemplos de envolvimento de indivíduos que podem contribuir para que se desenvolvam contextos de aprendizagem.

Admitindo essa mesma proposta, Imbernón (2010, p. 15), indica que o professor seja formado "por meio de capacidades reflexivas em grupo" que possam "abrir caminho para uma verdadeira autonomia profissional compartilhada, já que a profissão docente deve compartilhar o conhecimento com o contexto". O autor explica que processos coletivos de aprimoramento propiciam a revitalização profissional do professor. No mesmo sentido:

Grande parte das nossas intenções é inconsequente se a profissão continuar marcada por fortes tradições individualistas ou por rígidas regulações externas. Hoje, a complexidade do trabalho escolar exige o desenvolvimento de equipes pedagógicas. Existe a necessidade de integrar na cultura docente um conjunto de modos coletivos de produção e de regulação do trabalho (Nóvoa, 2012, p. 17).

Desse modo, cursos de formação propostos por grupos de pesquisas que já desenvolvem reflexão sobre a prática podem repercutir nesse modo coletivo de compartilhamento e aprimoramento de conhecimentos.

\section{ASPECTOS METODOLÓGICOS}

A pesquisa aqui descrita utilizou uma abordagem qualitativa. Tratou-se de um estudo de caso que investigou os resultados de um curso de formação de professores sobre o software Scratch. Para Gil (2002, p. 54), o estudo de caso "consiste no estudo aprofundado e exaustivo de um ou poucos objetos, de maneira que permita seu amplo e detalhado conhecimento". Nesse sentido, explorou-se com profundidade o processo formativo de um grupo de professores acerca do software Scratch. Essa modalidade de pesquisa é geralmente associada ao método qualitativo de investigação, embora também possa ser usada em abordagens quantitativas.

Segundo esta perspectiva, um fenômeno pode ser melhor compreendido no contexto em que ocorre e do qual é parte, devendo ser analisado numa perspectiva integrada. Para tanto, o pesquisador vai a campo buscando "captar" o fenômeno em estudo a partir da perspectiva das pessoas nele envolvidas, considerando todos os pontos de vista relevantes. Vários tipos de dados são coletados e analisados para que se entenda a dinâmica do fenômeno (Godoy, 1995, p. 21).

Concordando com a descrição de Godoy (1995) acerca da abordagem qualitativa e da necessidade de captar os fenômenos, uma das pesquisadoras foi a campo participar do curso de formação, realizando a observação participante. Segundo Moreira (2002, p. 52), a observação participante é "uma estratégia de campo que combina ao mesmo tempo a 
participação ativa com os sujeitos, a observação intensiva em ambientes naturais, entrevistas abertas informais e análise documental".

A pesquisadora, referida acima, se inscreveu no curso como cursista e realizou todas as atividades com os demais participantes. Nessa fase, fez o registro de cada encontro, de forma escrita e fotografada. Ao término do curso, todos os participantes desenvolveram um projeto no Scratch.

O curso ocorreu no período de agosto a novembro de 2017, na Universidade Tecnológica Federal do Paraná (UTFPR). Participaram do curso 14 pessoas, além de três formadoras. Neste artigo, os participantes estão identificados com a letra $\mathrm{P}$ e um número, para garantir a confidencialidade. Todos autorizaram a realização da pesquisa, assinando um Termo de Consentimento Livre e Esclarecido (TCLE).

Um ano após o fim do curso, os participantes foram entrevistados novamente, para que ocorresse a verificação da atual atuação docente e das relações dos professores com as TD e com o software Scratch. Optou-se por aguardar esse período para que a entrevista pudesse refletir as repercussões na prática profissional docente. A entrevista contou com as seguintes questões:

a) O curso trouxe contribuições para sua carreira profissional?

b) Você usou o software com seus estudantes após o curso? Ou outros softwares?

c) Você acha que o curso, de alguma maneira, contribuiu para que você esteja mais encorajado(a) a usar tecnologias digitais em sala de aula?

d) Qual sua impressão sobre o curso?

O processo do curso de formação e as respostas dadas às questões acima foram analisados, com o intuito de se identificar as possíveis contribuições do curso para os professores. Para a realização dessa análise, os entendimentos sobre formação continuada de Garcia (1999), Nóvoa (2012), Pimenta (2012), Tardif (2014), Romanowski (2007), Imbernón (2009, 2010), Mizukami (2006) e Fiorentini, Souza Junior e Melo (2003) serviram de aporte teórico.

Os dados das entrevistas foram analisados de acordo com o método de Análise de Conteúdo de Bardin (2016). Constituído o corpus da pesquisa, inicialmente foi realizada a pré-análise, a partir da leitura flutuante de todas as respostas dos professores. Em seguida, foram delimitadas as unidades de codificação dos dados, o que possibilitou a criação de três categorias, sendo elas: (a) Possibilidades de Reflexão; (b) Troca entre os pares; (c) Aprendizado docente. A última etapa da análise, a de interpretação e inferência, ocorreu a partir da análise das categorias, considerando tanto as respostas dos participantes como as observações do curso, como pode ser observado nas próximas seções. 


\section{O CURSO DE FORMAÇÃO SOBRE O SCRATCH}

Entre as pesquisas desenvolvidas nos últimos anos por integrantes do GPTEM, algumas tratam do software Scratch. Apesar disso, nem todos os participantes do grupo tinham conhecimentos específicos sobre essa ferramenta. Nas reflexões do GPTEM sobre sua utilização, surgiu a necessidade de um curso de formação. Assim, três integrantes do grupo, apoiadas pelo coordenador do grupo e um professor responsável apresentaram uma proposta junto à UTFPR, para a realização de um curso de Extensão intitulado Conhecendo o Scratch: algumas possibilidades de trabalho no Ensino de Matemática. As três formadoras eram, na época, mestrandas do Programa de Pós-Graduação em Educação em Ciências e em Matemática (PPGECM), da Universidade Federal do Paraná (UFPR). O curso, em um primeiro momento, objetivava instrumentalizar os participantes do curso, de modo a tornálos aptos a utilizar o Scratch para diversificar suas estratégias de ensino.

Após a aprovação do projeto pela UTFPR, o curso começou a ser divulgado. Primeiramente os integrantes do GPTEM foram comunicados. Na sequência, o convite foi estendido à comunidade de professores em geral, por meio de compartilhamento nas redes sociais e no site do grupo. Foram ofertadas 30 vagas. Os interessados no curso deveriam preencher uma ficha de inscrição que foi desenvolvida no Google Formulários. Houve 23 inscrições, sendo uma duplicada.

O curso, de caráter gratuito, teve duração de 21 horas presenciais e 21 horas a distância totalizando 42 horas, três horas presenciais a cada 15 dias. Apesar de 22 pessoas terem se inscrito, oito, que não participavam do GPTEM, nunca compareceram. Entre os participantes, sete atuavam na rede pública e seis na rede privada de ensino. Os participantes atuavam da Educação Básica ao Ensino Superior, e em atividades pedagógicas-administrativas como Coordenação pedagógica e Direção.

Algumas semanas antes do início do curso, a equipe responsável decidiu que, em concomitante à realização do curso, haveria leituras e discussões de textos sobre o Scratch e linguagens de programação semelhantes, de forma a enriquecer ainda mais o processo formativo. Segundo Imbernón (2010, p. 33), "a competência profissional, necessária em todo processo educativo, será formada em última instância na interação que se estabelece entre os próprios professores". Assim, a interação entre os cursistas ampliaria as possibilidades de aprimoramento profissional. 
Apresenta-se, no Quadro 1, as tarefas desenvolvidas no curso em cada encontro, pela letra $\mathrm{E}$, seguida de um número, que corresponde a ordem cronológica de acontecimentos do curso.

Quadro 1: Síntese dos encontros presenciais do curso

\begin{tabular}{|c|c|c|c|}
\hline Dia & Encontro & $\begin{array}{l}\text { Cursistas } \\
\text { presentes }\end{array}$ & Atividades desenvolvidas \\
\hline $16 / 08 / 17$ & E1 & 14 & $\begin{array}{c}\text { Explicação quanto ao formato do curso. } \\
\text { Organização do cronograma de responsáveis pela } \\
\text { apresentação dos textos a serem discutidos. } \\
\text { Apresentação da tela inicial do Scratch e das } \\
\text { principais funcionalidades do programa (planos de } \\
\text { fundo, sprites }{ }^{3} \text {, blocos de programação e movimento } \\
\text { de sprites). }\end{array}$ \\
\hline $30 / 08 / 17$ & E2 & 10 & $\begin{array}{l}\text { Aprofundamento dos conceitos de movimento dos } \\
\text { sprites e comunicação entre personagens. } \\
\text { Explicação e exemplos de efeitos de som e cores. }\end{array}$ \\
\hline 13/09/17 & E3 & 12 & $\begin{array}{c}\text { Apresentação da programação do jogo PacMan }{ }^{4} \\
\text { envolvendo comandos de aparência, movimento, } \\
\text { imagem e estruturas lógicas. }\end{array}$ \\
\hline $27 / 09 / 17$ & E4 & 11 & $\begin{array}{c}\text { Reflexões sobre programação no Scratch propostas } \\
\text { por uma das formadoras. } \\
\text { Apresentação de ferramentas geométricas no } \\
\text { programa. Início de programações dos projetos finais } \\
\text { individuais. }\end{array}$ \\
\hline $11 / 10 / 17$ & E5 & 6 & $\begin{array}{c}\text { Programação de projetos individuais, com discussões } \\
\text { entre os participantes e auxílio das formadoras sobre } \\
\text { as ferramentas necessárias em cada projeto. }\end{array}$ \\
\hline $25 / 10 / 17$ & E6 & 10 & Programações dos projetos finais pelos participantes. \\
\hline $08 / 11 / 17$ & E7 & 8 & $\begin{array}{l}\text { Mostra de um projeto programado por uma das } \\
\text { formadoras no Scratch. } \\
\text { Programação dos projetos finais pelos participantes. }\end{array}$ \\
\hline
\end{tabular}

Fonte: Dados da pesquisa (2020)

Embora alguns participantes não tenham comparecido em todos os encontros presenciais, eles puderam fazer as atividades à distância. Para tanto, acessavam um grupo criado no Facebook, no qual todos os cursistas podiam ler os textos propostos, bem como propor discussões sobre eles. Também ocorriam trocas de mensagens no WhatsApp do grupo de pesquisas. Assim, as discussões acerca do que ocorreu no encontro presencial se estendiam virtualmente.

\footnotetext{
${ }^{3}$ Sprites são os objetos gráficos ou personagens que se movimentam no Scratch.

${ }^{4}$ Jogo eletrônico bastante popular. Mais informações em: https://www.museudocomputador.org.br/historiapacman. Acesso em: 30 maio 2020.
} 


\section{DISCUSSÃO SOBRE O CURSO DE FORMAÇÃO}

No primeiro encontro do curso, as formadoras explicaram aos participantes que o curso teria momentos presenciais e à distância. Cada cursista deveria disponibilizar todas as suas tarefas, realizadas de forma à distância, em um grupo do Facebook, criado para esse fim. As formadoras comentaram, também, que haveria discussões de textos relevantes ao contexto do curso. Para isso, organizaram entre os presentes, um cronograma de responsáveis pelos textos sugeridos.

Nesse primeiro encontro, as próprias formadoras apresentaram um texto para leitura e incitaram as discussões. Os participantes tiveram um tempo para leitura e em seguida alguns principais pontos do texto foram levantados e discutidos. Após a análise do texto, foi apresentado o programa Scratch e demostrado suas principais funcionalidades. Uma das formadoras ia apresentando a programação no projetor, enquanto os participantes realizavam a mesma programação nos seus notebooks. Em seguida, foi definida a tarefa a ser feita à distância.

No segundo encontro, após a discussão sobre os textos, as formadoras aprofundaram alguns recursos do Scratch e procederam de forma semelhante ao primeiro encontro, mostrando como os cursistas deveriam executar cada ação.

Percebeu-se, nesses primeiros encontros, o caráter de instrumentalização criticado por Imbernón (2010). De fato, o objetivo prévio do curso era de instrumentalizar os cursistas para o uso do software. Contudo, as discussões já demonstravam que os professores que ali estavam, preocupavam-se com suas necessidades práticas de sala de aula. Eles questionaram de que forma poderiam ensinar sobre o Scratch para seus estudantes. Essas inquietações vêm ao encontro da menção de Nóvoa (2012) sobre a necessidade de propostas teóricas contemplarem as carências docentes.

No terceiro encontro, houve discussão sobre os textos e diálogo sobre os temas presentes. Foi aprofundado a ideia de pensamento computacional e os professores conversaram sobre as novas propostas curriculares que exigem que essa habilidade seja desenvolvida nos estudantes. Logo após os diálogos sobre os textos, uma das formadoras apresentou a programação de um jogo, semelhante ao PacMan. A formadora pediu que uma tela de fundo fosse desenhada, mostrando o caminho para esse tipo de construção. Em seguida, informou que os cursistas deveriam desenhar seu personagem, com características mais personalizadas. 
A programação de movimento desse personagem foi mostrada para que fosse repetida pelos participantes, que demonstraram dificuldades em localizar os blocos que deveriam ser usados e em compreender os objetivos de tais blocos. Alguns cursistas, inclusive, sugeriram que a abordagem precisaria ser alterada nos próximos encontros para um melhor aproveitamento do curso, pois apenas a instrução de como deveria ser feita a programação estava sendo insuficiente para a compreensão. Por esse motivo, as formadoras decidiram que mudariam a maneira como conduziriam os próximos encontros, de forma a proporcionar mais autonomia aos cursistas. Nesse momento, o objetivo do curso se alterou e não focava mais a instrumentalização. As discussões sobre os textos revelavam a preocupação sobre a compreensão acerca do papel das TD no ambiente escolar.

A situação acima mostra que uma abordagem de curso de formação que não privilegiou a autonomia do professor foi criticada pelos participantes. Isso revela a necessidade de um planejamento de curso que contribua para que os professores sejam evidenciados, como destacam Pimenta (2012) e Imbernón (2009).

A partir dessa situação, a dinâmica do curso mudou. Houve explicações sobre o software e suas funcionalidades de forma mais ampla, sem um determinado procedimento a ser repetido pelos cursistas. No quarto encontro, após discussões sobre textos, ao tentarem explorar o Scratch, os cursistas dialogavam bastante, interferindo nas programações dos colegas, em processos de parceria, como indicam Fiorentini, Souza Junior e Melo (2003). As discussões relacionaram as programações que estavam sendo desenvolvidas com as possíveis contribuições para a aprendizagem. Começaram a surgir propostas para a sala de aula e os professores contribuíam uns com os outros nos diferentes níveis de ensino que atuavam. Nesse sentido, o curso estava repercutindo em possíveis inovações na prática, tal como citado por Romanowski (2007).

Os textos discutidos no quinto encontro tratavam sobre habilidades que poderiam ser desenvolvidas pelos estudantes ao usarem o Scratch. Os participantes exemplificaram suas falas com exemplos de suas práticas de sala de aula ou na gestão. A partir desse encontro, os cursistas começaram a desenvolver seus projetos finais. As três formadoras passaram a circular pela sala, de modo a esclarecer dúvidas e auxiliar os participantes na programação de seus projetos, que deveria avançar durante a semana à distância.

No sexto encontro além de discussões acerca de um texto, os participantes foram convidados a dar continuidade na programação de seus projetos. As formadoras ofereciam suporte aos cursistas que iam desenvolvendo tanto a parte visual do projeto quanto a 
programação computacional. Nesse encontro, muitas programações avançaram consideravelmente. Na Figura 1, apresenta-se alguns exemplos de programações dos cursistas. Na imagem, pode-se observar dois participantes desenvolvendo seus projetos finais.

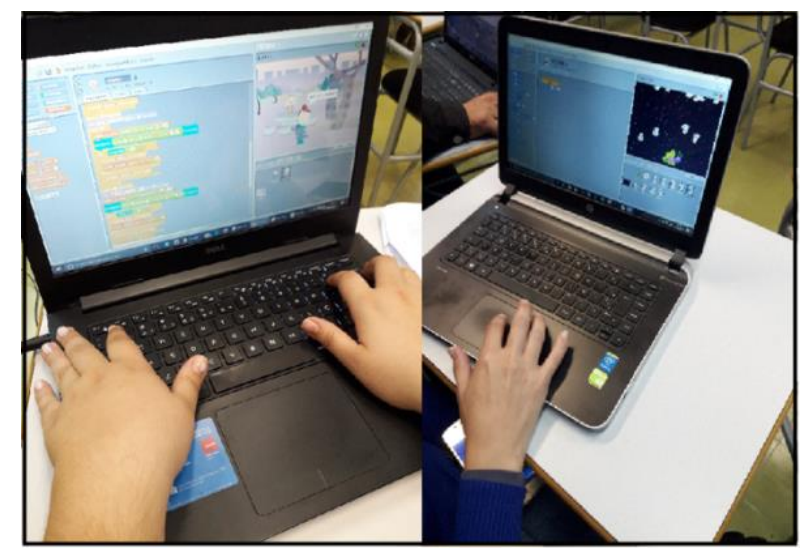

Figura 1: Programação realizada pelos cursistas Fonte: Dados da pesquisa (2020)

No último encontro, ao invés de discussão de texto, ocorreu a apresentação de uma das formadoras sobre o seu trabalho de mestrado. Tendo em vista a aproximação de sua defesa, ela compartilhou com o grupo detalhes sobre sua pesquisa, que versa sobre o Scratch. Os participantes puderam dar sugestões e fazer perguntas sobre o trabalho e tiveram a oportunidade de ver um projeto do Scratch já desenvolvido. Foi mais um momento de perceber a importância da coletividade nos processos formativos. A inter-relação, como indicada por Garcia (1999), contribuiu para que a pesquisadora aprimorasse sua dissertação, ao mesmo tempo que sua apresentação contribuiu para que os cursistas compreendessem ainda mais o software.

\section{ANÁLISE dOS RELATOS DOS PROFESSORES APÓS O CURSO DE FORMAÇÃO}

A leitura flutuante realizada nas respostas da entrevista feita com todos participantes um ano após a conclusão do curso possibilitou que fossem delimitadas as unidades de registro e, por conseguinte, estabelecidas três categorias de análise, conforme mencionouse na descrição dos aspectos metodológicos. São elas: 
(a) Possibilidades de Reflexão (Cat_1): refere-se às percepções dos pesquisadores sobre as reflexões manifestadas pelos professores participantes em relação ao curso;

(b) Troca entre os pares (Cat_2): trata das inferências acerca das contribuições coletivas proporcionadas a partir do curso de formação;

(c) Aprendizado docente (Cat_3): refere-se aos indícios revelados na análise de aprendizagem docente acerca do software Scratch ou uso de outas TD.

As unidades de registro delimitadas foram reescritas em forma de texto por um dos pesquisadores envolvidos na investigação e a ação foi validada pelos pares. Os registros da Cat_1 estão disponíveis no Quadro 2.

Quadro 2: Relatos dos professores e Cat_1

\begin{tabular}{|c|c|c|c|c|}
\hline Participante & Relato & Cat_1 & Cat_2 & Cat_3 \\
\hline P2 & $\begin{array}{l}\text { Informou que usou várias possibilidades do Scratch em } \\
\text { sala de aula, tanto com recursos programados por ele, } \\
\text { como incentivando a programação por seus estudantes. } \\
\text { Acrescentou que as reflexões realizadas em grupo } \\
\text { sobre a importância do desenvolvimento do } \\
\text { pensamento computacional contribuíram para que ele } \\
\text { inserisse esse e demais softwares de programação em } \\
\text { suas aulas. }\end{array}$ & $x$ & & \\
\hline P4 & $\begin{array}{l}\text { Comentou sobre as possibilidades que teve por meio do } \\
\text { curso, tanto em sua vida profissional como acadêmica. } \\
\text { Usou na aplicação para estudantes de Ensino Médio e } \\
\text { Superior. Também destacou as reflexões que } \\
\text { ocorreram a partir dos textos lidos, mencionando que } \\
\text { repercutem em suas práticas atuais. }\end{array}$ & $x$ & & \\
\hline P10 & $\begin{array}{l}\text { Destacou que o curso trouxe possibilidades de } \\
\text { programação intuitiva para que explorasse com seus } \\
\text { estudantes. Comentou que as reflexões o encorajaram } \\
\text { a escrever seu projeto de mestrado e o incentivaram à } \\
\text { pesquisa. }\end{array}$ & $x$ & & \\
\hline P12 & $\begin{array}{l}\text { Não atua em sala, mas tem divulgado o software para } \\
\text { professores. Destacou os momentos de reflexão do } \\
\text { curso. }\end{array}$ & $x$ & & \\
\hline P13 & $\begin{array}{l}\text { Não atua em sala, mas destaca que as reflexões o } \\
\text { levaram a pensar em novas formas de uso das TD no } \\
\text { contexto escolar. }\end{array}$ & $x$ & & \\
\hline
\end{tabular}

Fonte: Dados da pesquisa (2020)

Com relação à primeira categoria, Possibilidades de Reflexão, notou-se que os participantes destacaram que as leituras e discussões ocorridas no curso, os levaram a refletir sobre a própria prática. Nota-se, nesse sentido, que a formação contribuiu para que ocorressem momentos reflexivos sobre a prática, citados por Imbernón (2010) como fundamentais aos processos formativos. 
Nas respostas dos participantes, identificou-se que a formação se refletiu em processos de mudanças, como destacado por Garcia (1999), Imbernón (2010) e Romanowski (2007). Essas mudanças estão relacionadas com a inserção de novas TD em sala de aula e podem ser percebidas, por exemplo, quando o P2 cita que a partir das reflexões no curso, ele inseriu o Scratch e outros softwares em suas atividades didáticas.

Analisando essa categoria sob o viés da observação participativa, nota-se que os momentos oportunizados para debates e leituras foram relevantes para que se permitissem essas reflexões.

A análise da segunda categoria, Troca entre pares, revela que dois fatores, especialmente, contribuíram para que o aprendizado coletivo ocorresse, conforme percebido na observação do curso. O primeiro deles se relaciona ao fato de os projetos desenvolvidos no curso terem sido compartilhados. Essa proposta converge com os apontamentos de Nóvoa (2012) ao citar os modos coletivos de produção relativos à formação docente. Outra condição que possibilitou a troca entre pares foi a utilização de uma rede social para o curso, pois isso favoreceu o contato entre os participantes, mesmo quando findado o processo formativo.

Com relação aos relatos dos professores, as unidades de registro estão apresentadas no Quadro 3.

Quadro 3: Relatos dos professores e Cat_2

\begin{tabular}{|c|c|c|c|c|}
\hline Participante & Relato & Cat_1 & Cat_2 & Cat_3 \\
\hline $\mathrm{P} 6$ & $\begin{array}{l}\text { Citou que já conhecia o software e que não atua na } \\
\text { Educação Básica, por isso não utilizou com seus } \\
\text { estudantes. Mesmo considerando que já era encorajado } \\
\text { a utilizar TD antes do curso, o participante destaca que } \\
\text { a troca com os pares é enriquecedora para a prática } \\
\text { docente. }\end{array}$ & & $\mathrm{x}$ & \\
\hline P7 & $\begin{array}{l}\text { Informou que após o curso de formação, ministrou um } \\
\text { curso para demais professores e que também utilizou } \\
\text { com estudantes. Pontuou que as discussões de textos } \\
\text { tornaram o curso ainda mais relevante. Também } \\
\text { afirmou que utilizou os projetos dos seus colegas do } \\
\text { curso com os seus estudantes. }\end{array}$ & & $\mathrm{x}$ & \\
\hline P8 & $\begin{array}{l}\text { Mencionou a reorganização pessoal para programar o } \\
\text { seu aprendizado com o software. Não atua em sala no } \\
\text { momento, mas está disposto a usar TD quando retornar } \\
\text { para o exercício da docência. O participante destacou } \\
\text { as parcerias desenvolvidas no curso, que repercutiu no } \\
\text { seu ingresso no mestrado. }\end{array}$ & & $\mathrm{x}$ & \\
\hline P11 & $\begin{array}{l}\text { Informou que já conhecia o Scratch, mas que não } \\
\text { conhecia as possibilidades para a sala de aula. } \\
\text { Destacou que tem usado na formação de professores e } \\
\text { que os colegas do curso continuam contribuindo com } \\
\text { compartilhamento de informações sobre TD. }\end{array}$ & & $\mathrm{x}$ & \\
\hline
\end{tabular}

Fonte: Dados da pesquisa (2020) 
As falas dos participantes relacionadas a essa segunda categoria demonstram que as trocas entre pares foram relevantes para o processo formativo. O aprendizado coletivo, vivenciado em um grupo de pesquisa, contribuiu para que esses professores permanecessem em pesquisas e compartilhamento de conhecimentos. Nesse sentido, alguns cursistas relataram que o curso contribuiu para o ingresso no mestrado. Percebe-se que esses professores estão sendo os autores de sua formação, tal como sugerido por Tardif (2014).

A última categoria se refere ao aprendizado docente com relação às TD. Considerando a observação participativa, notou-se que todos os professores conseguiram manipular o software e desenvolver projetos, o que caracteriza um domínio sobre a ferramenta. Além disso, mesmo durante o curso, percebeu-se o interesse pela busca por outros softwares semelhantes, que se relacionassem ao Pensamento Computacional. Tal busca, também ficou evidenciada na entrevista, como percebe-se no Quadro 4, que apresenta as unidades de registro relativas à Cat_3.

Quadro 4: Relatos dos professores e Cat_3

\begin{tabular}{|c|c|c|c|c|}
\hline Participante & Relato & Cat_1 & Cat_2 & Cat_3 \\
\hline $\mathrm{P} 1$ & $\begin{array}{l}\text { Sinalizou as contribuições do grupo, destacando o } \\
\text { software explorado e as discussões dos textos. } \\
\text { Mencionou que utilizou o software com seus estudantes } \\
\text { e outros recursos semelhantes. Tem realizado } \\
\text { pesquisas sobre as TD e continua engajado em } \\
\text { processos formativos. }\end{array}$ & & & $\mathrm{x}$ \\
\hline P3 & $\begin{array}{l}\text { Destacou as mudanças que teve com relação ao seu } \\
\text { próprio processo de ensino, já que enquanto estudante } \\
\text { do curso percebeu que o processo de aprendizagem } \\
\text { não é simples. Com relação ao software, tem } \\
\text { desenvolvido atividades de programação com os } \\
\text { estudantes. }\end{array}$ & & & $\mathrm{x}$ \\
\hline P5 & $\begin{array}{l}\text { Mencionou que não conhecia o software anteriormente } \\
\text { e que, mesmo com o curso, permaneceu com certa } \\
\text { dificuldade com relação a ele. Mas que devido aos } \\
\text { momentos de diálogos, sentiu-se encorajado a tentar } \\
\text { usar com os estudantes e tem desenvolvido projetos } \\
\text { simples com eles. O participante considera que o curso } \\
\text { influenciou significativamente sua relação com as TD } \\
\text { como recursos para a sala de aula. }\end{array}$ & & & $\mathrm{x}$ \\
\hline P9 & $\begin{array}{l}\text { Comentou que não conhecia o Scratch. Tem aplicado o } \\
\text { curso na rede pública estadual, pois achou muito } \\
\text { relevante. Utiliza constantemente o software com os } \\
\text { estudantes. }\end{array}$ & & & $\mathrm{x}$ \\
\hline P14 & $\begin{array}{l}\text { Afirmou que usa constantemente TD em sala de aula, } \\
\text { após a formação sobre o software e as discussões que } \\
\text { ocorreram no grupo. Afirmou que compreendeu a } \\
\text { importância do pensamento computacional e que isso o } \\
\text { estimulou a buscar outras formações e softwares. }\end{array}$ & & & $\mathrm{x}$ \\
\hline
\end{tabular}

Fonte: Dados da pesquisa (2020) 
As buscas por outros recursos e outras formações, evidenciadas nas falas de alguns participantes entrevistados, refletem o desenvolvimento da autonomia docente, mencionada por Fiorentini et al. (2003), quando comentam que a formação deve instigar esses docentes a criarem novas estratégias e inovações.

O curso possibilitou que os sujeitos envolvidos conhecessem um novo recurso para a sala de aula. Para aqueles que já conheciam o software, ocorreu ampliação do conhecimento acerca das funcionalidades do Scratch. Contudo, destaca-se a resposta do $\mathrm{P} 5$, sobre a constante dificuldade com o software, mesmo após o curso. Observa-se a necessidade de um processo contínuo de formação, assim como pontua Mizukami (2006).

Esses resultados nos dão indícios de que, embora os professores que participaram do curso de formação já usassem TD, seus envolvimentos com as tecnologias foram aprimorados após o processo formativo, seja devido às discussões ocorridas, às reflexões proporcionadas ou à relação entre a teoria e a prática estabelecida.

\section{CONSIDERAÇÕES}

A pesquisa desenvolvida objetivou verificar as possíveis contribuições de um curso de formação de professores sobre o Scratch na atuação profissional dos participantes.

Analisando essas contribuições, percebeu-se que todos os participantes do curso usaram o software durante sua atuação em sala de aula, como formadores de professores ou como divulgadores do uso das TD.

Notou-se que o curso surgiu a partir da necessidade de um grupo de professores sobre o software e desencadeou em autonomia para explorar esse e demais recursos digitais. Assim, o curso, tal como proposto por Pimenta (2012), teve a prática docente como ponto de partida e chegada.

Uma dificuldade observada no processo foi que mesmo que o curso tenha sido aberto à comunidade em geral com divulgação nas redes sociais, não houve um número grande de inscritos. Isso impediu, por exemplo, que a análise pudesse identificar professores com mais dificuldades sobre o uso de TD, uma vez que os inscritos já possuíam um determinado conhecimento prévio sobre essas tecnologias.

Entre as contribuições verificadas, além da autonomia frente ao uso das TD, podese destacar a possibilidade de reflexão sobre a prática, o incentivo na busca de softwares que possibilitem o Pensamento Computacional, o encorajamento à pesquisa e a 
continuidade de processos formativos, a divulgação do software a outros professores e o compartilhamento dos projetos desenvolvidos.

A flexibilidade mostrada pelas formadoras, ao modificarem a metodologia do curso, foi fundamental para que os resultados apresentados fossem alcançados. Também se considera como acertada a inserção de textos para discussões pelo grupo em concomitante com as atividades, pois eles suscitaram reflexões pertinentes sobre a prática docente com uso das TD. Nesse cenário, as formações para o uso de softwares e demais TD não devem se limitar a processos de instrumentalização, mas devem repercutir em oportunidades de discussão, reflexão e verdadeira mudança da prática docente.

Espera-se que a pesquisa aqui relatada contribua para que profissionais responsáveis por formação continuada de professores levem em consideração as reais necessidades de sala de aula, bem como a autonomia docente, ao proporem cursos e programas.

Sugere-se que outras pesquisas relacionadas à formação continuada de professores para uso de TD sejam desenvolvidas, especialmente sobre o software Scratch, que possibilita o desenvolvimento do Pensamento Computacional, tema emergente nas discussões de pesquisadores da Educação Matemática. Pesquisas que analisem a prática do professor em sala de aula, após processos formativos, podem trazer novas contribuições e compreensões para os dados aqui apresentados.

Também se almeja que professores que desejem usar TD em sala se sintam encorajados a permanecerem em constante processo de formação, para que essas tecnologias possam trazer mudanças significativas para os processos de ensino e aprendizagem.

\section{REFERÊNCIAS}

Bardin, L. (2016). Análise de Conteúdo. 3 reimp. 1 ed. São Paulo: Edições 70 Brasil.

Belloni, M. L. (1999). Mediatização - Os desafios das novas tecnologias de informação e comunicação. In: Belloni, M. L. Educação a Distância. (pp. 53-77). Campinas: Editora Autores Associados.

Borba, M. C., Silva, R. S. R. \& Gadanidis, G. (2016). Fases das tecnologias digitais em Educação Matemática. 1 ed. Belo Horizonte: Autêntica Editora.

Brasil (2014). Plano Nacional de Educação. Brasília: MEC/Secretaria de Educação Básica. 
Brasil (2017). Base Nacional Comum Curricular: Educação Infantil e Ensino Fundamental. Brasília: MEC/Secretaria de Educação Básica.

Farias, A. P. (2017). O Software de Programação Scratch na Formação Inicial do Professor de Matemática por Meio da Criação de Objetos de Aprendizagem. (Dissertação de Mestrado). Universidade Tecnológica Federal do Paraná, PR.

Fiorentini, D., Souza Junior, A. J. \& Melo G. F. A. de (2003). Saberes docentes: um desafio para acadêmicos e práticos. In: Geraldi, C. M. G., Fiorentini, D. \& Pereira, E. M. de A. (orgs.) Cartografia e trabalho docente: professor(a)-pesquisador(a). 2 ed. Campinas, SP: Mercado das Letras.

Garcia, C. M. (1999). Formação de professores: para uma mudança educativa. Porto: Porto Editora.

Gil, A. (2002). Como elaborar projetos de pesquisa. 4 ed. São Paulo: Atlas.

Godoy, A. S. (1995). Introdução à pesquisa qualitativa e suas possibilidades. Revista de administração de empresas, v. 35, n.2, 57 - 63.

Imbernón, F. (2009). A. formação do professorado deve potencializar a identidade docente. In.: Imbernón, F. Formação permanente do professorado: novas tendências. (pp. 72-78). São Paulo: Cortez.

Imbernón, F. (2010). Formação docente e profissional: formar-se para a mudança e incerteza. 8 ed. São Paulo: Cortez.

Kenski, V. M. (2011). Educação e tecnologias: O novo ritmo da informação. 8 ed. São Paulo: Papirus.

Moreira, D. A. (2002). O método fenomenológico na pesquisa. São Paulo: Pioneira Thomson.

Mizukami, M. G. N. (2006). Aprendizagem da docência: conhecimentos específicos, contextos e práticas pedagógicas. In: Nacarato, A. M. \& Paiva, M. A. V. A formação do professor que ensina matemática. (pp. 213 - 231). Belo Horizonte: Autêntica, 2006.

Nóvoa, A. (2012). Para una formación de profesores construída dentro de la profesión. Revista de Educación, 350. Septiembre-diciembre, 203 - 218.

Pimenta, S. G. (2012). Formação de professores: identidade e saberes da docência. In. Pimenta, S. G. (org.). (pp. 15 - 72). Saberes pedagógicos e atividade docente. 8 ed. São Paulo: Cortez.

Resnick, M. et al. (2009). Scratch: Programming for All. Communications of the ACM. Vol. 52 N. $11,60-67$.

Richit, A., Mocroski, L. F. \& Kalinke, M. A. (2016). Tecnologias e prática pedagógica em Matemática: tensões e perspectivas evidenciadas no diálogo entre três estudos. In: 
Kalinke, M. A \& Mocroski, L. F (orgs.). Lousa digital \& outras tecnologias na Educação Matemática. (pp. 117 - 140). Curitiba: CRV.

Rocha, A. K. O. (2015). A programação de computadores como meio para integrar diferentes conhecimentos: uma experiência com professores de Matemática (Tese de Doutorado). Universidade Anhanguera de São Paulo, SP.

Rocha, F. S. M. (2018). Análise de projetos do Scratch desenvolvidos em um curso de formação de professores. (Dissertação de Mestrado). Universidade Federal do Paraná, PR.

Romanowski, J. P. (2007). Formação e profissionalização docente. 3 ed. Curitiba: Ibpex.

Tardif, M. (2014). Saberes Docentes e formação profissional. 17 ed. Petrópolis, RJ: Editora Vozes.

\section{TÍTULO DA OBRA}

\section{NOTAS}

Formação continuada de professores de matemática para uso de tecnologias digitais: uma análise a partir de um curso de extensão sobre o software scratch

Flavia Sucheck Mateus da Rocha

Mestre em Educação em Ciências e em Matemática

Centro Universitário Internacional Uninter, Curitiba, PR. Professora.

fsucheck@yahoo.com.br

(D) https://orcid.org/0000-0001-6803-8898

Tânia Teresinha Bruns Zimer

Doutora em Educação

Universidade Federal do Paraná, Curitiba, PR. Professora Associado.

taniatbz@gmail.com

(1) http://orcid.org/0000-0002-9353-7944

\section{Sérgio Camargo}

Doutor em Educação para a Ciência

Universidade Federal do Paraná, Curitiba, PR. Professor Associado.

s1.camargo@gmail.com

(1) https://orcid.org/0000-0001-8766-5424

Marcelo Souza Motta

Doutor em Ensino de Ciências e Matemática

Universidade Tecnológica Federal do Paraná, Curitiba, PR. Professor Adjunto.

msmotta27@gmail.com

(D) https://orcid.org/0000-0001-5534-2735

Endereço de correspondência do principal autor

Travessa Amapá, 26. São José dos Pinhais, PR. Cep 83010-590. Brasil.

\section{AGRADECIMENTOS}

Agradecemos aos professores de matemática participantes do curso de formação, que possibilitaram a investigação descrita no artigo.

\section{CONTRIBUIÇÃO DE AUTORIA}

Concepção e elaboração do manuscrito: F. S. M. Rocha, T. T. B. Zimer, S. Camargo, M. S. Motta.

Coleta de dados: F. S. M. Rocha.

Análise de dados: F. S. M. Rocha, T. T. B. Zimer, M. S. Motta.

Discussão dos resultados: F. S. M. Rocha

Revisão e aprovação: T. T. B. Zimer, M. S. Motta

\section{CONJUNTO DE DADOS DE PESQUISA}

Todo o conjunto de dados que dá suporte aos resultados deste estudo foi publicado no próprio artigo. 
FINANCIAMENTO

Não se aplica.

\section{CONSENTIMENTO DE USO DE IMAGEM}

Não se aplica

\section{APROVAÇÃO DE COMITÊ DE ÉTICA EM PESQUISA \\ Não se aplica}

\section{CONFLITO DE INTERESSES}

Não se aplica

LICENÇA DE USO - uso exclusivo da revista

Os autores cedem à Revemat os direitos exclusivos de primeira publicação, com o trabalho simultaneamente licenciado sob a Licença Creative Commons Attribution (CC BY) 4.0 International. Estra licença permite que terceiros remixem, adaptem e criem a partir do trabalho publicado, atribuindo o devido crédito de autoria e publicação inicial neste periódico. Os autores têm autorização para assumir contratos adicionais separadamente, para distribuição não exclusiva da versão do trabalho publicada neste periódico (ex.: publicar em repositório institucional, em site pessoal, publicar uma tradução, ou como capítulo de livro), com reconhecimento de autoria e publicação inicial neste periódico.

PUBLISHER - uso exclusivo da revista

Universidade Federal de Santa Catarina. Grupo de Pesquisa em Epistemologia e Ensino de Matemática (GPEEM). Publicação no Portal de Periódicos UFSC. As ideias expressadas neste artigo são de responsabilidade de seus autores, não representando, necessariamente, a opinião dos editores ou da universidade.

EDITOR - uso exclusivo da revista

Méricles Thadeu Moretti e Rosilene Beatriz Machado

HISTÓRICO - uso exclusivo da revista

Recebido em: 03-06-2020 - Aprovado em: 10-02-2021 